\title{
Management of neuropathic urinary incontinence in children by intermittent catheterisation
}

\author{
JOHN E S SCOTT AND S DEEGAN \\ Department of Surgery, University of Newcastle upon Tyne, Newcastle upon Tyne
}

SUMMARY Forty-nine children with urinary incontinence owing to neuropathic bladder were treated by intermittent catheterisation. Manometric studies to determine urethral closing pressures and intravesical pressure/volume relationships were performed before or during treatment in all children. Cystography and intravenous urography were carried out at the beginning of treatment and intravenous urography was repeated after treatment for at least 12 months. Routine long-term antibacterial therapy was not used. With a 3-hourly catheterisation regimen a total of $46(93 \%)$ children achieved day-time control but $27(55 \%)$ did so only with the help of propantheline or imipramine or both of these. Night-time control was also substantially improved in $43(87 \%)$ children. The manometric studies enabled a reliable prediction to be made on whether drugs would be required to achieve success. One child with an undilated urinary tract before treatment developed unilateral dilatation owing to mechanical problems during treatment. Upper urinary tract dilatation which was present before treatment in 20 children ( 33 kidneys) disappeared or improved in all. Early renal failure in 2 children also responded favourably. The technique had to be abandoned in 2 children.

Intermittent catheterisation (IC), as a method of managing urinary retention and incontinence in patients with traumatic spinal cord lesions, was first advocated by Guttmann and Frankel. ${ }^{1}$ The good results obtained with the technique were subsequently confirmed by others. ${ }^{2-7}$ More recently, encouraging reports have appeared on the use of IC in children with urinary incontinence due to congenital spinal anomalies. ${ }^{8-14}$ The purpose of this paper is to report on a consecutive series of 49 children treated by IC since the policy was introduced with reference to the measurement of intravesical pressure/volume relationships and urethral closing pressures, the effect of pharmacological agents on the neuropathic bladder, urographic changes after 12 months' treatment, the management of bacteriuria, and the control of incontinence.

\section{Patients}

The spinal cord lesions which caused the incontinence were congenital (spina bifida) in $\mathbf{4 8}$ and traumatic in one.

Age and sex. There were 22 boys and 27 girls. The majority were aged between 5 and 16 years when treatment with IC was started. Some would undoubtedly have started treatment earlier had the method been available. Perhaps the best time to start treatment is just before the child starts school, although much depends on the willingness of the child and his parents to accept the method, and on the state of the child's upper urinary tract. The latter factor led to the decision to start treatment in one infant who had urinary retention, infection, upper urinary tract dilatation, and renal failure.

Paralysis. Twenty-seven children, of whom 15 were boys, had complete bilateral lower limb paralysis and had been confined to wheelchairs for most of their lives. These boys had hitherto used penile urinals but as they became older their obesity and spinal deformities increased to the point when their urinals were ineffective. Paralysis in the remaining children was less extensive so that they were able to walk, although most of them had orthopaedic appliances.

Radiology and renal function. Intravenous urography and cystography were performed in all children before starting IC. The upper urinary tracts were 
normal in 29, 7 had unilateral dilatation (one of a solitary kidney), and 13 bilateral dilatation. Ureteric reflux was present unilaterally in 9 and bilaterally in 4. In only one child with reflux was the upper urinary tract not dilated.

Evidence of renal failure was present in 2 children. In one the blood urea level was $15.2 \mathrm{mmol} / 1(91.6$ $\mathrm{mg} / 100 \mathrm{ml})$, in the other it was $16.6 \mathrm{mmol} / \mathrm{l}(100$ $\mathrm{mg} / 100 \mathrm{ml})$.

Vesical and urethral manometry. Initially, cystometrography was performed by a simple technique using a balloon catheter connected to a central venous pressure manometer. It soon became clear that this method provided an incomplete assessment of the behaviour of the lower urinary tract. Thus a more sophisticated method using a strain gauge and direct writer was substituted; this provided measurements of urethral closing pressure together with continuous records of bladder pressure during filling. A size 5 FG side-hole catheter connected via the strain gauge to a syringe driver producing a flow of $1 \mathrm{ml} / \mathrm{min}$ was passed into the empty bladder. The catheter was slowly withdrawn by hand along the urethra and the closing pressure recorded on the direct writer. At least three recordings were made in each child. This catheter was then replaced in the bladder and used to record intravesical pressure during filling through a second size 5 or 8 FG catheter passed alongside it. A radiographic contrast medium was used for the infusions enabling the urinary tract to be screened simultaneously. Thus the outline of the bladder could be seen and the relationship between ureteric reflux, if any, and intravesical pressure determined.

Training in intermittent catheterisation technique. Having completed their radiographic and manometric examinations the children were seen in a special 'catheter clinic' by a stoma/catheter therapist. The principles and technique of intermittent catheterisation were explained and demonstrated to the mother and child, a written sheet of instructions issued, and a supply of catheters provided. The catheters supplied for the girls were made from polyethylene tubing in sizes 10,12 , and $14 \mathrm{FG}$, presterilised in plastic envelopes. This material was used because it was sufficiently rigid to enable the catheter to be inserted with one hand, but sufficiently flexible to avoid damaging the insensitive vulva while attempting to locate the urethral orifice. Furthermore, the material was cheap and the catheters could be semi-disposable. Boys were provided with polyvinyl Nelaton catheters of appropriate size, also presterilised and semi-disposable. Instructions were given to rinse the catheters in running tap water before and after use and to place them in a bowl of sodium hypochlorite (Milton) solution overnight. A plastic envelope was supplied with the catheters as a day-time container; each catheter was used for one week.

Most boys, and the older girls, soon learnt to catheterise themselves: a mirror on a flexible stand was particularly useful in demonstrating to the girls their vulval anatomy. The objective was to eliminate day-time wetting completely with an interval between catheterisation of not less than 3 hours. This interval was convenient in the children's daily lives at school and home, and provided a little leeway. If wetting occurred less than 3 hours after catheterisation the use of pharmacological agents was considered.

Use of drugs. If 3-hourly catheterisation did not control wetting, 2 drugs were used as an adjunct: propantheline, an anticholinergic agent which inhibits smooth muscle activity, and imipramine, a tricyclic antidepressant with $\alpha$-adrenergic properties reputed to increase tone in the bladder neck and posterior urethra although it may act through other mechanisms. The drugs were given in the mornings and early afternoons in doses of up to $30 \mathrm{mg}$ propantheline and $25 \mathrm{mg}$ imipramine.

Antibiotics and bacteriuria. Intermittent catheterisation is a 'clean' rather than an aseptic technique, so bacteriuria is an almost inevitable consequence. No attempt was made to maintain sterile urine by continuous antibacterial therapy. In the author's experience in children with neuropathic bladder or urinary diversions such therapy was not successful and indeed, promoted the appearance of highly antibiotic-resistant organisms. By keeping the urinary tract effectively drained it was felt that the presence of organisms in the urine was probably of no significance provided that symptoms of an active urinary infection were absent. Furthermore, withholding antibiotics bred a growth of organisms which were fully sensitive to a wide range of these drugs. Thus if symptoms did appear it was possible to eliminate both symptoms and organisms with a 7day course of an oral antibiotic. This policy was not altered in the presence of reflux since regular and complete emptying of the urinary tract should compensate for this factor.

\section{Results}

Control of incontinence. It was the relationship between intravesical and urethral closing pressures that was the important factor governing the success or failure of IC in controlling incontinence. Ideally, 
the urethral closing pressure had to be higher than the intravesical pressure at (depending on the child's size) minimal volumes of $100-150 \mathrm{ml}$ (Fig. 1). If it was not, catheterisation had to be performed at inconveniently frequent intervals to prevent urine leaking out of the bladder (Fig. 2). Some children with low intravesical pressures were wet because urethral closing pressures were also low. The exact opposite was found in other children who had high,

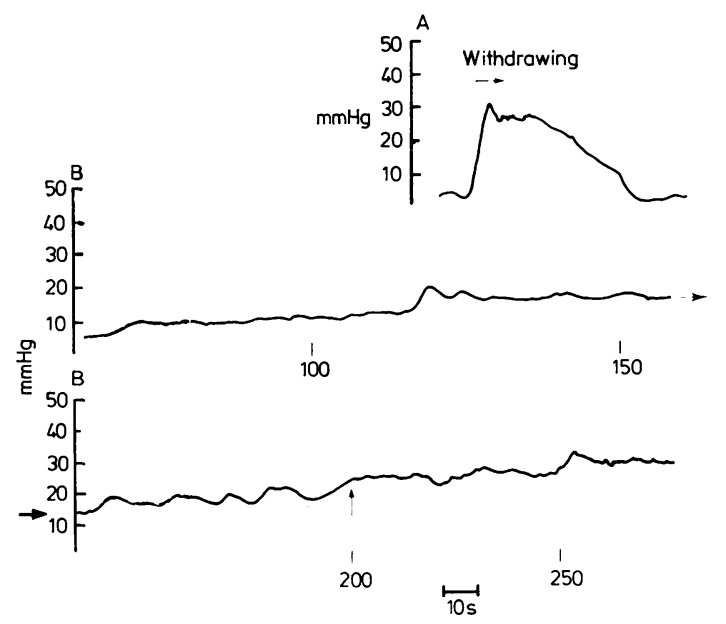

Fig. 1 Tracings of urethral closing pressure $(A)$ and cystometrogram $(B)$. Urethral closing pressure exceeds intravesical pressure at high volumes.

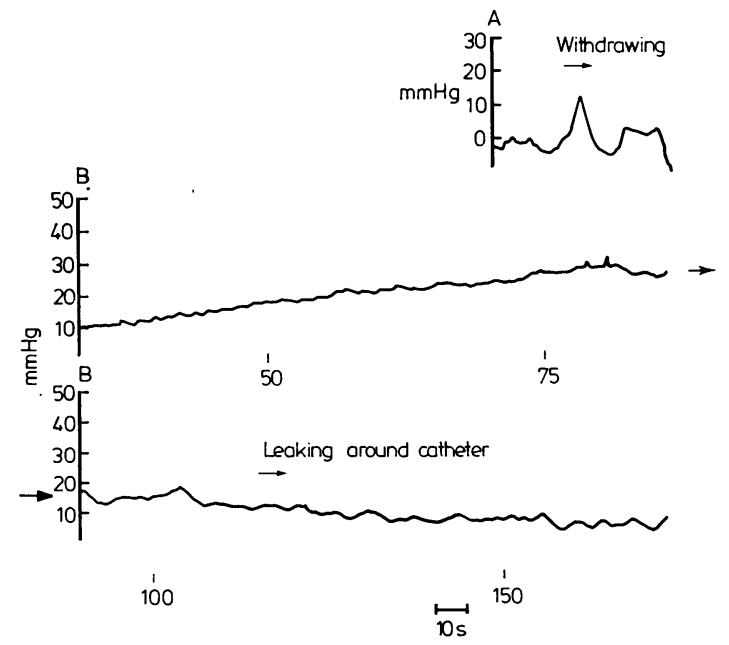

Fig. 2 Tracings of urethral closing pressure $(A)$ and cystometrogram $(B)$. Urethral closing pressure is lower than intravesical pressure at low volume. often fluctuating intravesical pressures but were dry because they also had high urethral closing pressures. In some cases reflux occurred to such a degree as substantially to reduce intravesical pressure. In fact the pressure being recorded was not so much intravesical pressure as pressure in the whole upper urinary tract (Fig. 3a and b).

To assess its effectiveness, all children were started on IC before anticholinergic drugs were given. This enabled the manometric tests to be evaluated for predicting which children would require anticholinergic drugs. Control of incontinence was graded as follows: (a) Dry day and night. (b) Dry by day, damp at night. (c) Dry by day, wet at night. (d) Damp by day, wet at night. (e) Wet day and night.

Eight children had grade (a) control and 11 grade (b) without the help of drugs. Since day-time control was the main objective of IC, these $19(39 \%)$ children were regarded as successful. Urethral closing pressure was measured in 16 and was higher than intravesical pressure (low in 12, high in 4) in all. Of the 29 children in whom IC was not successful in controlling incontinence, 24 had high intravesical pressures and 5 had low, 3 of whom also had low urethral closing pressures; in the remaining 2 , this measurement was not made before drugs were prescribed for them. Thus there was good correlation between the results of cystometrographic and urethral closing pressure measurements and the success of IC in controlling incontinence.

Of the children in whom IC failed to control incontinence, 25 were given propantheline and imipramine, 1 propantheline only, and 3 imipramine only. Two of the 3 given imipramine had low intravesical and urethral closing pressures and the drug was given in the hope of improving urethral tone and thus control. Side effects of the drugssuch as drowsiness, hot flushes, or vomiting-were present in 8 children and necessitated reduction of the dose in 5 , stopping imipramine in 1 , propantheline in 1 , and both drugs in one. Ultimately with the help of drugs, 11 children achieved grade (a) control, 13 grade (b), 3 grade (c), one grade (d).

Altogether, of 48 children with neuropathic bladder over age 5 years, control of incontinence of grades (a) and (b) was achieved in $43(89 \%)$, and of grade (c) in $3(6.5 \%)$. Only 2 children were complete failures.

Bacteriuria. Significant bacteriuria was found in 42 children at every culture and in 4 children intermittently. The most common organism r.tured was Escherichia coli which appeared in 34 children, followed by Klebsiella sp. which was present in 14, and Proteus sp. in 8 . Sometimes 2 organisms were 


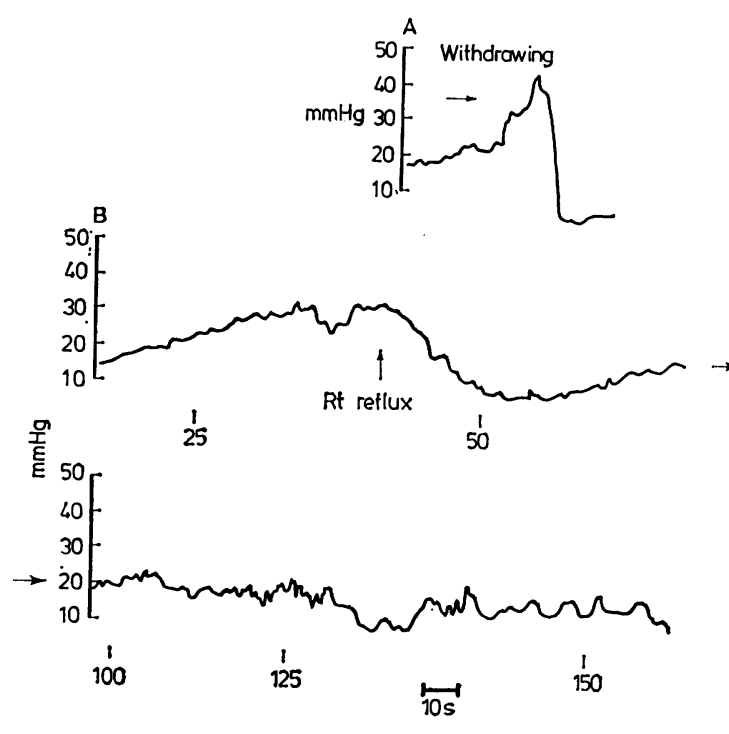

Fig. 3a Tracings of urethral closing pressure $(A)$ and cystometrogram $(B)$. Shows effect of ureteric reflux on intravesical pressure. Note high urethral closing pressure.
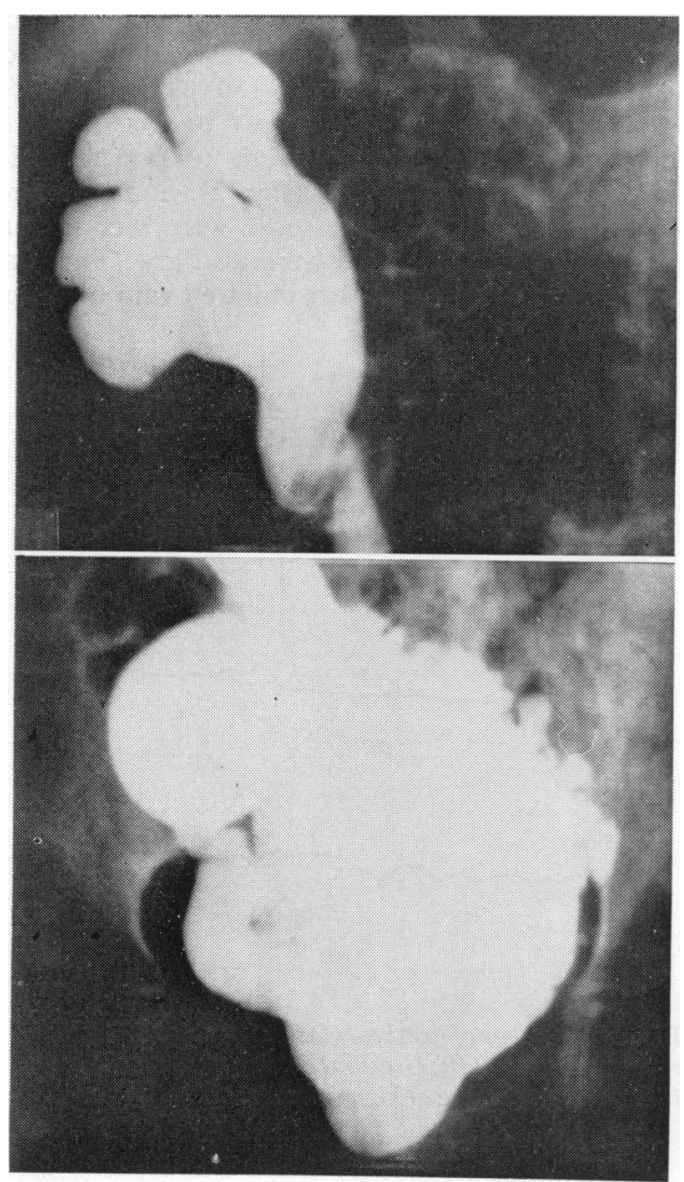

Fig. 3b Cystogram of same child showing right ureteric reflux. cultured from the same child ana there was a tendency for the organisms to change from time to time. Four children were having long-term antibacterial therapy, one had sterile urine but the others were infected. Two children had sterile urine without antibiotic therapy. Symptoms suggesting an active urinary infection occurred occasionally in 6 children who were treated with short courses of the appropriate antibiotic.

Complications of catheterisation. With one exception all the boys learnt to catheterise themselves as did 9 girls. The remainder were catheterised by or with the help of their mothers or the school nurse. One 16year-old girl who was being successfully catheterised by her mother refused to learn how to catheterise herself so that the method had to be abandoned and an indwelling catheter used when she entered a residential educational college. Thus $61 \%$ of the children were successfully managing their urinary incontinence without help. Two boys encountered difficulties with inserting their catheters: one found it easier after he had changed to a smaller sized catheter but the other developed an obstruction in his bulbar urethra which could easily be passed with a metal bougie but not with a flexible catheter. Retrograde urethrography showed a mucosal pocket on the dorsal wall of the bulbar urethra in which the catheter tip was tending to catch. The boy also had a high intravesical pressure and was unable to tolerate either propantheline or imipramine, even in small doses. Eventually a permanent perineal urethrostomy 
was established enabling an indwelling catheter to be used.

Radiographic follow-up. All children were subjected to intravenous urography at least one year after starting IC. Of 29 children with normal upper urinary tracts before IC, one developed dilatation of one ureter and kidney. Eight years previously this ureter had been reimplanted into the bladder to relieve a ureterovesical junction obstruction. Cystoscopy showed that a paraureteric diverticulum had developed, the neck of which had a muscular collar which compressed the intramural ureter when the bladder was emptied. The diverticulum was excised and one year later the ureter had returned to its original size. Upper tract dilatation, which was present in 20 children (33 kidneys) at the start of IC, disappeared or was substantially reduced in every case.

Effect of drugs on vesical and urethral manometry. Sixteen children who were given drugs to help control their incontinence were re-examined manometrically about one year after starting treatment. It was not possible in all the children to make direct comparisons between pre- and post-treatment examinations because the technique differed. However, some observations seemed justifiable.

Two boys who were wet despite low intravesical pressures at high volumes were presumed to have low urethral closing pressures. This was improved by taking imipramine (Fig. 4). In one child having propantheline only it was found that the amplitude of the vesical contractions was reduced so that a

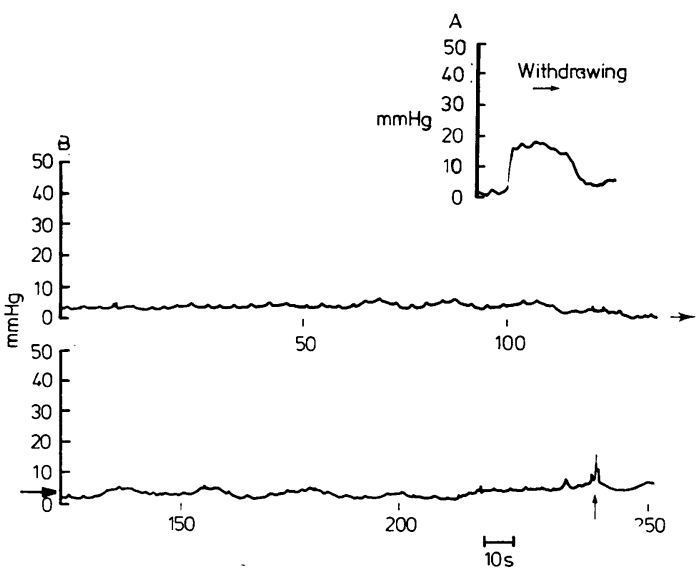

Fig. 4 Tracings of urethral closing pressure $(A)$ ard cystometrogram $(B)$. With imipramine, urethral closing pressure exceeds intravesical pressure.

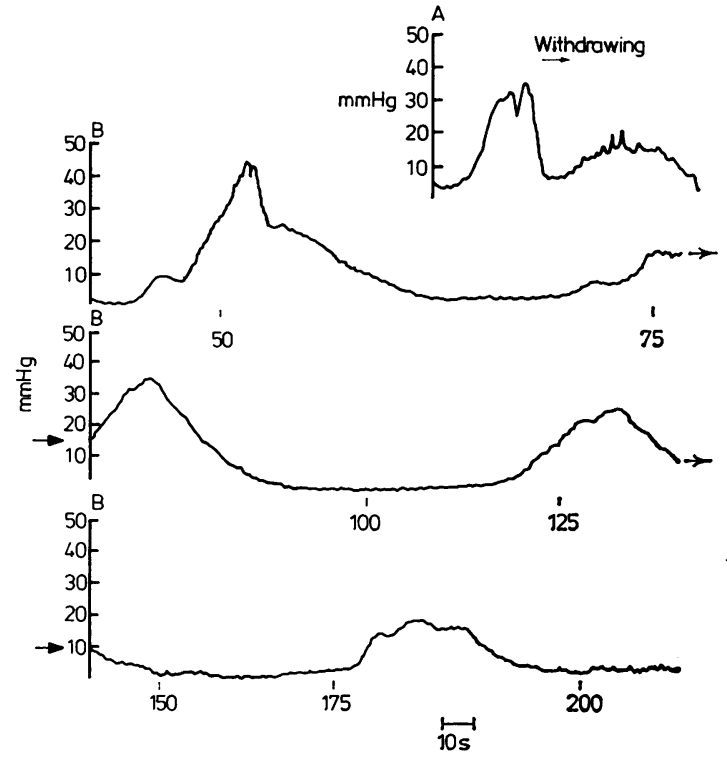

Fig. 5 Tracings of urethral closing pressure $(A)$ and cystometrogram $(B)$. Child taking propantheline alone. There are slow bladder contractions diminishing in amplitude with filling. Urethral closing pressure remains high.

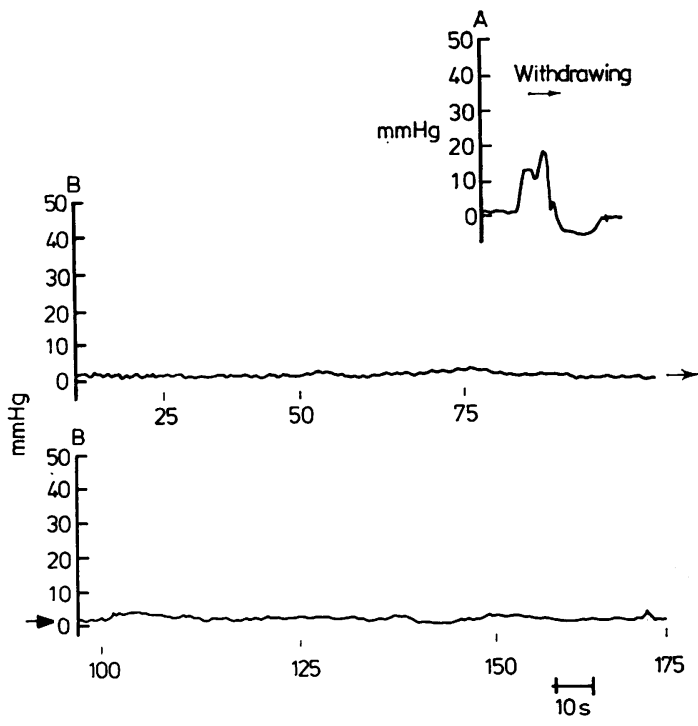

Fig. 6 Tracings of urethral closing pressure $(A)$ and cystometrogram $(B)$. Child is taking propantheline and imipramine. Intravesical pressure low, bladder contractions eliminated. Urethral closing pressure exceeds intravesical pressure. 
series of slow pressure waves occurred without a reduction in urethral closing pressure (Fig. 5). Ten of 12 children having both imipramine and propantheline had flat, low pressure tracings (Fig. 6) whereas previously without the drugs strong bladder contractions had occurred. The remaining 2 children had high intravesical pressures but so also were their urethral closing pressures.

In so far as it was possible to interpret these findings, it seemed that imipramine alone raised the urethral closing pressure and propantheline alone reduced but did not abolish vesical contractions. A combination of both drugs in most cases reduced vesical contractions while maintaining a satisfactory urethral closing pressure.

\section{Discussion}

In this series of 49 children with neuropathic urinary incontinence, IC successfully controlled day-time incontinence in $46(93 \%)$ and improved night-time incontinence as well in $43(87 \%)$. However, only 19 $(39 \%)$ achieved this degree of control without the help of drugs. It is therefore, clear that manometric studies of the bladder and urethra are essential before recommending IC as a method of controlling neuropathic urinary incontinence. These studies enable an accurate prediction to be made on whether drugs will be necessary to achieve success. Disappointment and loss of motivation from what may initially appear to be failure of IC to control incontinence can on the basis of manometric findings be avoided either by starting the drugs at the same time as IC or at least by warning the child and his parents that they will almost certainly be necessary. Thirty $(61 \%)$ learnt to catheterise themselves without help and so became independent in so far as the management of their incontinence was concerned. The broadening of the horizons of their lives, particularly from the social and educational aspects, was most impressive. The technique of IC itself produced no complications and persistent bacteriuria was found to be of no significance in most of them: continuous antibacterial therapy was not required.

Particularly gratifying were the short-term results of IC on the state of the upper urinary tract. In the space of one year, only one child developed dilatation, for which an obvious mechanical reason was discovered, and the condition of 20 with pre-existing dilatation improved. The blood urea level in the 2 children with raised levels at the start of IC fell to $5 \cdot 1 \mathrm{mmol} / 1(30.7 \mathrm{mg} / 100 \mathrm{ml})$ and $7.0 \mathrm{mmol} / 1(42.2$ $\mathrm{mg} / 100 \mathrm{ml}$ ). Renal function remained normal in all the other children.

These results confirm the findings of previous workers: intermittent catheterisation is the method of choice for controlling incontinence and upper urinary tract deterioration in children with neuropathic bladder. The majority of these children also eventually learn to control their faecal incontinence by a variety of methods so that it becomes possible for them to discard their bags, pads, nappies, and plastic pants and to wear normal clothing. Furthermore, the technique obviates the need for the expensive and time-consuming urinary diversion operations hitherto performed for neuropathic incontinence; nor need expensive urinary collecting appliances be provided.

Catheters were supplied by Downs Surgical Limited, Church Path, Mitcham, Surrey.

\section{References}

1 Guttmann L, Frankel $H$. The value of intermittent catheterisation in the early management of traumatic paraplegia and tetraplegia. Paraplegia 1966; 4: 63-84.

2 Comarr A E. Intermittent catheterisation for the traumatic cord bladder. J Urol 1972; 108: 79-81.

3 Lapides J, Diokno A C, Silber S J, Lowe B S. Clean intermittent self-catheterisation in the treatment of urinary tract disease. J Urol 1972; 107: 458-61.

4 Perkash I. Intermittent catheterization. The urologist's point of view. J Urol 1974; 111 : 356-60.

5 Perkash I. Intermittent catheterization and bladder rehabilitation in spinal cord injury patients. $J$ Urol 1975; 114: 230-3.

- Herr $\mathbf{H ~ W . ~ I n t e r m i t t e n t ~ c a t h e t e r i z a t i o n ~ i n ~ n e u r o g e n i c ~}$ bladder dysfunction. $J$ Urol $1975 ; 113$ : 477-9.

7 Firlit C F, Canning J R, Lloyd F A, Cross R R, Brewer R, $\mathrm{Jr}$. Experience with intermittent catheterization in chronic spinal cord injury patients. $J$ Urol $1975 ; 114: 234-6$.

8 Lyon R P, Scott M D, Marshall S. Intermittent catheterization rather than urinary diversion in children with meningomyelocele. J Urol 1975; 113: 409-17.

9 Laptides J, Diokno A C, Gould F R, Lowe B S. Further observations on self-catheterization. J Urol 1976; 116: 169-71.

10 Raezer D M, Benson G S, Wein A J, Duckett J W, Jr. The functional approach to the management of the pediatric neuropathic bladder. A clinical study. J Urol 1977; 117: 649-54.

11 Light $\mathrm{K}$, van Blerk P J P. Intermittent catheterisation in congenital neurogenic bladder. A preliminary report. Br J Urol 1977; 49: 523-6.

12 Hilwa N, Perlmutter A D. The role of adjunctive drug therapy for intermittent catheterization and self-catheterization in children with vesical dysfunction. $J$ Urol 1978; 119: $551-4$.

13 Withycombe J, Whitaker $R$, Hunt G. Intermittent catheterisation in the management of children with neuropathic bladder. Lancet 1978; ii: 981-3.

14 Kass E J, McHugh T, Diokno A. Intermittent catheterization in children less than 6 years old. J Urol 1979; 121 : 792-3.

Correspondence to Mr John E S Scott, Department of Surgery, Royal Victoria Infirmary, Newcastle upon Tyne NE1 4LP.

Received 22 June 1981 